\title{
O ENSINO DE ESTATÍSTICA E A PERCEPÇÃO DE ESTUDANTES SOBRE O IMPACTO DO USO DOS AGROTÓXICOS
}

\section{STATISTICS TEACHING AND STUDENTS 'PERCEPTION ON THE IMPACT OF THE USE OF AGROTOXICS}

\author{
Sidnéia Almeida Silva ${ }^{1}$ \\ Irene Mauricio Cazorla ${ }^{2}$
}

\begin{abstract}
Resumo: Este trabalho tem como objetivo analisar o desenvolvimento e implementação de uma sequência de ensino que visou a apropriação dos conceitos estatísticos em contexto, tendo por tema agrotóxicos. Tratase de uma pesquisa de intervenção, pautada no letramento estatístico proposto por Gal (2002) e no ciclo investigativo de Wild e Pfannkuch (1999), além das orientações de Gil (2008) e Vieira e Dalmoro (2008) na construção da escala Likert. Participaram do estudo 46 estudantes de um colégio situado em um município produtor de hortifrúti e consumidor de agrotóxicos. Os resultados mostram que os estudantes se envolveram em todo o processo investigativo, realizaram atividades estatísticas, deram sentido aos resultados encontrados e aguçaram sua consciência no cuidado com o meio ambiente, alimentos e saúde.
\end{abstract}

Palavras-chave: Educação Matemática; Ensino de Estatística; Ciclo Investigativo; Letramento Estatístico; Agrotóxico.

Abstract: This work aims to analyze the development and implementation of a teaching sequence that aimed at the appropriation of statistical concepts in context, with the theme of pesticides. It is an intervention research, based on the statistical literacy proposed by Gal (2002) and the investigative cycle of Wild and Pfannkuch (1999), in addition to the guidelines of Gil (2008) and Vieira and Dalmoro (2008) in the construction of the Likert scale. 46 students from a school located in a horticultural producer and pesticide consumer city participated in the study. The results show that students were involved in the entire investigative process, they performed statistical activities, gave meaning to the results found and sharpened their awareness in caring for the environment, food and health.

Keywords: Mathematical Education; Teaching Statistics. Investigative Cycle. Statistical Literacy. Pesticide.

\section{Introdução}

Segundo a Base Nacional Comum Curricular - BNCC (BRASIL, 2018, p. 463), para formar os estudantes do Ensino Médio “como sujeitos críticos, criativos, autônomos

\footnotetext{
${ }^{1}$ Licenciada em Matemática com Enfoque em Informática, Universidade Estadual do Sudoeste da Bahia (UESB). Mestranda no Programa de Pós-Graduação em Educação em Ciências e Matemática (PPGECM). Universidade Estadual de Santa Cruz (UESC), Ilhéus, Bahia, Brasil. E-mail: siasilva@uesc.br

2 Mestre em Estatística e Doutora em Educação, Universidade Estadual de Campinas (UNICAMP), Professora Plena da Universidade Estadual de Santa Cruz (UESC), Ilhéus, Bahia, Brasil. E-mail: icazorla@uol.com.br
} 
DOI: https://doi.org/10.33238/ReBECEM.2020.v.4.n.4.24142

e responsáveis", as escolas devem "proporcionar experiências e processos que lhes garantam as aprendizagens necessárias para a leitura da realidade, o enfrentamento dos novos desafios da contemporaneidade (sociais, econômicos e ambientais) e a tomada de decisões éticas e fundamentadas". Para isso, devemos apresentar aos estudantes o mundo como campo a ser investigado, visando um posicionamento crítico quanto aos aspectos políticos, sociais, produtivos, ambientais e culturais, de modo que se sintam estimulados a equacionar e resolver questões que interferem na sua vida e na de sua comunidade.

Ademais, a BNCC orienta que ao ensinarmos Matemática devemos desenvolver competências, das quais destacamos a $7^{\mathrm{a}}$ :

\begin{abstract}
Argumentar com base em fatos, dados e informações confiáveis, para formular, negociar e defender ideias, pontos de vista e decisões comuns que respeitem e promovam os direitos humanos, a consciência socioambiental e o consumo responsável em âmbito local, regional e global, com posicionamento ético em relação ao cuidado de si mesmo, dos outros e do planeta. (BRASIL, 2018, p. 9).
\end{abstract}

O ensino de Estatística pode proporcionar uma leitura de mundo para uma formação crítica, desenvolvendo a capacidade questionadora dos estudantes, mas para isso é preciso elaborar atividades que criem condições favoráveis para desenvolver essa capacidade, como preconizam Wodewotzki e Jacobini (2004).

No contexto da disciplina de Educação Estatística, do curso de Mestrado em Educação em Ciências e Matemática (PPGECM) da Universidade Estadual de Santa Cruz (UESC) e em parceria com o D-Estat, fomos desafiados a elaborar e implementar uma intervenção de ensino, envolvendo conceitos e procedimentos estatísticos, nas escolas onde atuamos como professores. No nosso caso, em particular, a escola fica localizada em Jaguaquara, um município do Vale do Jiquiriçá, referência na produção de hortifrúti e que utiliza grande quantidade de agrotóxicos, o que auxiliou para a escolha do tema.

O D-Estat é um projeto de pesquisa intitulado de "Desenvolvimento Profissional de Professores que Ensinam Matemática, D-Estat" (SANTANA; CAZORLA, 2018). Desse modo, essa investigação seguiu todas as recomendações éticas e está registrada na Plataforma Brasil sob o protocolo 85950217.6.1001.5526.

O Território de identidade Vale do Jiquiriçá compreende 21 municípios, incluindo o município em questão, que juntos, constituem o que seria a parte interiorana da Bacia Hidrográfica Vale do Jiquiriçá. O território foi criado pela política federal da SDT/MDA em 2004 e transformado em unidade de planejamento pelo governo do Estado da Bahia em 2007, conforme UNEB/SEPLAN No 004/2008. 


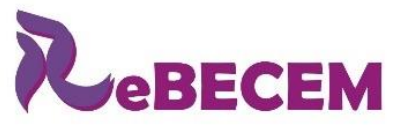

DOI: https://doi.org/10.33238/ReBECEM.2020.v.4.n.4.24142

Assim formulamos a questão de investigação: Como uma intervenção de ensino, pautada no letramento estatístico e no ciclo investigativo, promove a aprendizagem de conceitos estatísticos em contexto? E definimos como objetivo, analisar o desenvolvimento e implementação de uma sequência de ensino que visou a apropriação dos conceitos estatísticos em contexto, tendo por tema agrotóxicos e com base no letramento estatístico e no ciclo investigativo.

Para atingir os objetivos propostos construímos uma sequência de ensino utilizando os conceitos estatísticos e uma Escala de Percepção do Impacto do uso dos Agrotóxicos - EPIA, seguindo as orientações de Gil (2008) e Vieira e Dalmoro (2008). Como referencial teórico recorremos ao Letramento Estatístico proposto por Gal (2002) e seguimos as fases do Ciclo Investigativo proposto por Wild e Pfannkuch (1999). A intervenção de ensino foi desenvolvida com estudantes de uma turma de $3^{\circ}$ ano do Ensino médio de um colégio estadual.

Para a apresentação dos resultados alcançados, este artigo está dividido em sete seções: Na primeira seção há a introdução deste trabalho; na segunda seção apresentamos o problema do uso de agrotóxicos no Brasil e na região onde está inserido o colégio; na terceira seção expomos as orientações curriculares sobre os conteúdos de Estatística no Ensino Médio; na quarta seção apresentamos o marco teórico do estudo, tendo em conta o letramento estatístico de Gal (2002) e o ciclo investigativo de Wild e Pfannkuch (1999); na quinta seção detalhamos o percurso metodológico, indicando o perfil dos participantes, procedimentos, o delineamento da sequência de ensino e a construção da Escala de Percepção do Impacto do uso dos Agrotóxicos - EPIA; na sexta seção apresentamos o desenvolvimento da sequência de ensino com a produção dos estudantes, além de exibir a análise das respostas à escala EPIA antes e depois da intervenção, a fim de verificar possíveis mudanças na percepção dos estudantes; e, por último, na sétima seção tecemos as considerações finais.

\section{Os agrotóxicos}

O Brasil é um grande produtor agrícola e um dos países que mais utiliza agrotóxicos, apresentando casos de contaminação ao meio ambiente, nos alimentos e à saúde humana. Segundo a legislação vigente, os agrotóxicos são definidos como: 
DOI: https://doi.org/10.33238/ReBECEM.2020.v.4.n.4.24142

[...] os produtos e os agentes de processos físicos, químicos ou biológicos, destinados ao uso nos setores de produção, no armazenamento e beneficiamento de produtos agrícolas, nas pastagens, na proteção de florestas, nativas ou implantadas, e de outros ecossistemas e também de ambientes urbanos, hídricos e industriais, cuja finalidade seja alterar a composição da flora ou da fauna, a fim de preservá-las da ação danosa de seres vivos considerados nocivos. (BRASIL, 1989, Art. $2^{\circ}$ ).

Segundo o Instituto Brasileiro do Meio Ambiente e dos Recursos Naturais Renováveis (IBAMA), no histórico de comercialização de agrotóxicos entre os anos de 2000 e 2018, observa-se um considerável aumento no consumo destes, especialmente nos últimos anos, conforme Figura 1.

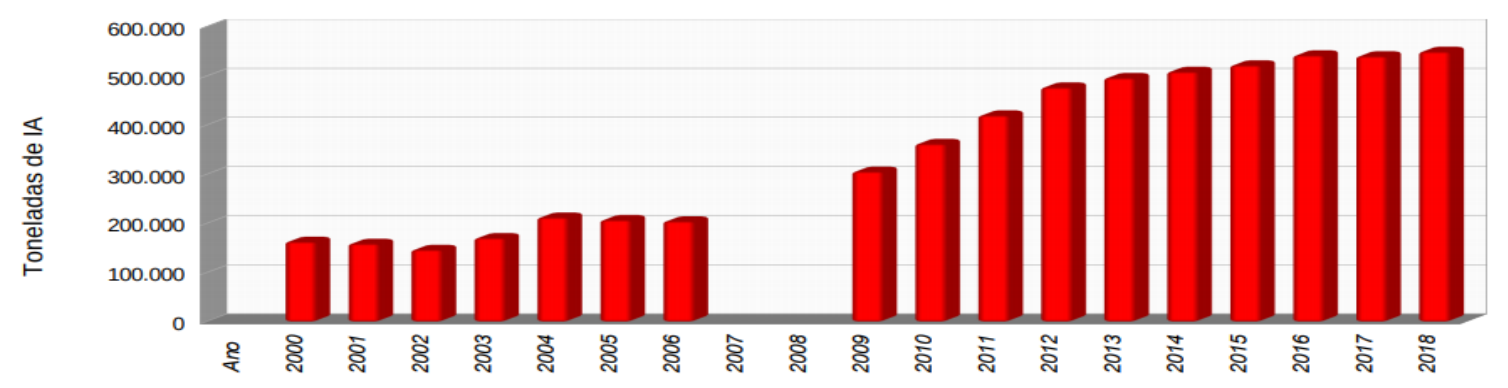

Figura 1: Consumo de Agrotóxicos e afins pelo Brasil no período de 2000 a 2018.

Fonte: Dados fornecidos pelas empresas que registram produtos técnicos, agrotóxicos e afins, conforme art. 41 do Decreto 4.074/2002, IBAMA (2019).

Segundo o Instituto Nacional de Câncer (INCA, 2009), com base em resultados divulgados pela Organização Mundial de Saúde (OMS), observa-se um registro de 20 mil mortes por ano devido ao contato direto ou indireto com os agrotóxicos. Com base nos mesmos resultados, o Brasil, país com maior consumo destes produtos desde 2008, por conta do agronegócio, sofre com uma série de problemas, como por exemplo a permissão de agrotóxicos e da venda ilegal de produtos que já foram proibidos em outros países.

O INCA (2009) acrescenta que a exposição aos agrotóxicos pode causar uma série de doenças, afetando os agricultores e trabalhadores das indústrias que fabricam esses produtos e de toda a população por meio de consumo de alimentos e água contaminados. O INCA destaca, também, a partir dos estudos nacionais e internacionais, que a contaminação por agrotóxicos vai além da contaminação dos alimentos, da terra, das águas, afetando também os seres humanos e aumentando a incidência de câncer.

Como visto, o tema agrotóxico envolve questões vinculadas ao meio ambiente, alimentação e saúde humana. Um tema rico para ser explorando no ambiente escolar. Por exemplo, sua abordagem no ensino de Ciências é destacada por Fernandes e Stuani (2015, p. 759), ao concluir que abordar esse tema pode desenvolver nos estudantes "a capacidade 


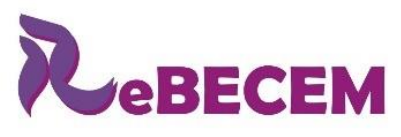

Revista Brasileira de Educação em

Ciências e Educação Matemática

DOI: https://doi.org/10.33238/ReBECEM.2020.v.4.n.4.24142

de argumentação e poder de decisão, análise e posicionamento crítico e prática social diante de temas que interferem em suas vidas".

Como o colégio onde trabalhamos está inserido em um município produtor de hortifrúti e consumidor de agrotóxicos, vimos a oportunidade de ensinar Estatística discutindo com os estudantes que vivenciam esse problema cotidianamente. No sentido de compreender como percebem as dimensões do uso dos agrotóxicos ou se estão alienados. No caso de estarem alienados, organizar meios de despertar suas consciências e ao mesmo tempo ensinar os conceitos estatísticos.

Na próxima seção apresentamos as orientações curriculares sobre o ensino de Estatística no Ensino Médio que pautou a construção da sequência de ensino.

\section{Orientações curriculares para os conteúdos de Estatística no Ensino Médio}

A BNCC é um documento de caráter normativo que orienta o ensino das etapas e modalidades da Educação Básica. O Ensino Médio é etapa final da Educação Básica e visa garantir a consolidação e o aprofundamento dos conhecimentos adquiridos no Ensino Fundamental, favorecendo a preparação básica para o trabalho e cidadania, de modo que aconteça o "desenvolvimento de competências que possibilitem aos estudantes inserir-se de forma ativa, crítica, criativa e responsável em um mundo do trabalho cada vez mais complexo e imprevisível” (BRASIL, 2018, p. 465).

No Ensino Médio o foco é a construção de uma visão integrada da Matemática, aplicada à realidade, em diferentes contextos. Um dos caminhos para contemplar esse alinhamento seria a Educação Estatística que, segundo Wodewotzki e Jacobini (2004), é um processo que favorece a contextualização das informações, como também oferece oportunidades relevantes para reflexões e para críticas.

Dentre as habilidades propostas pela BNCC (BRASIL, 2018, p. 533) destacamos a seguinte: “Analisar tabelas, gráficos e amostras de pesquisas estatísticas apresentadas em relatórios divulgados por diferentes meios de comunicação [...]”. No intuito de atender a essa habilidade, em um dos momentos do desenvolvimento da sequência de ensino, os estudantes tiveram acesso a um mapa interativo que apresentava dados estatísticos sobre a quantidade de agrotóxicos detectados na água potável que abastece mais de 2.300 cidades do Brasil, no período de 2014 a 2017. Além disso, distribuímos nove reportagens com temas relacionados aos agrotóxicos, contendo dados estatísticos. Os temas foram 


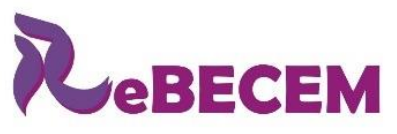

\section{Revista Brasileira de Educação em \\ Ciências e Educação Matemática}

DOI: https://doi.org/10.33238/ReBECEM.2020.v.4.n.4.24142

referentes aos impactos desses produtos químicos na contaminação dos alimentos, na saúde e no meio ambiente. Os estudantes foram orientados a discutir e expor suas considerações em relação às reportagens que receberam a fim de subsidiar os conceitos estatísticos trabalhados na intervenção de ensino.

Outras habilidades contempladas foram: "Construir e interpretar tabelas e gráficos de frequências com base em dados obtidos em pesquisas por amostras estatísticas [...]”, e "Planejar e executar pesquisa amostral sobre questões relevantes, usando dados coletados diretamente ou em diferentes fontes, e comunicar os resultados por meio de relatório contendo gráficos [...]" conforme apresentado na BNCC (BRASIL, 2018, p. 546).

As habilidades citadas foram trabalhadas na etapa da sequência de ensino em que os estudantes utilizaram seus próprios dados - resultado do preenchimento da Escala EPIA antes da intervenção -, na construção de tabelas de distribuição de frequência (TDF) e gráficos sobre as questões envolvidas na escala. As questões eram referentes a argumentos sobre agrotóxicos, sua presença nos alimentos, comprometimento à saúde da população e ao meio ambiente. A produção dos estudantes representava suas percepções sobre o tema, o quanto estavam ou não conscientes sobre os agrotóxicos e os danos causados por estes.

Contemplando para além das habilidades Matemáticas com foco no Ensino de Estatística, a sequência de ensino também proporcionou a participação dos estudantes em ações para investigar desafios e tomar decisões éticas e socialmente responsáveis, a partir da análise de problemas sociais, como os que envolvem situações de saúde, conforme a BNCC (BRASIL, 2018). Em grupo, os estudantes tiveram oportunidade de discutir sobre problemas de saúde como consequência do contato direto e indireto com agrotóxico, como também socializaram as experiências e casos reais com uso destes produtos.

A contextualização dos conhecimentos da Estatística superou a simples exemplificação de conceitos de gráficos e tabelas com fatos ou situações cotidianas, como proposto pela BNCC (BRASIL, 2018), pois, valorizou a aplicação dos conhecimentos na vida dos estudantes, favorecendo seu protagonismo no enfrentamento de questões sobre saúde, alimentação e meio ambiente, fato que atende a outra habilidade da BNCC, vinculada a Ciências da Natureza e suas Tecnologias no Ensino Médio, como a de:

\footnotetext{
Avaliar os benefícios e os riscos à saúde e ao ambiente, considerando a composição, a toxicidade e a reatividade de diferentes materiais e produtos, como também o nível de exposição a eles, posicionando-se criticamente e propondo soluções individuais e/ou coletivas para seus usos e descartes responsáveis. (BRASIL, 2018, p.555)
} 
DOI: https://doi.org/10.33238/ReBECEM.2020.v.4.n.4.24142

Essa habilidade foi explorada quando foram discutidas as questões ambientais, vinculadas ao uso de agrotóxicos, na água potável de 271 municípios da Bahia, como apresentado em reportagem do Correio, editada por Lyrio e Vigné (2019). A cidade onde moram os estudantes, aparece listada com a ocorrência de 15 agrotóxicos na água. Ainda foram abordadas reportagens relacionadas ao agrotóxico, à contaminação do ar, à fragilidade e redução da fertilidade do solo, todos apresentando dados estatísticos.

Explorar questões sobre o meio ambiente é também recomendação da Lei $n^{\circ}$ 9.795, de 27 de abril de 1999 que dispõe sobre a Educação Ambiental em que:

Art. 2o A Educação Ambiental é um componente essencial e permanente da educação nacional, devendo estar presente, de forma articulada, em todos os níveis e modalidades do processo educativo, em caráter formal e não-formal. (BRASIL, 1999, Art. 2).

Sobre os objetivos fundamentais da Educação Ambiental, segundo a Lei 9.795/99 (BRASIL, 1999, Art. 5, III), ressalta-se "o estímulo e o fortalecimento de uma consciência crítica sobre a problemática ambiental e social”.

Na próxima seção apresentamos o aporte teórico no qual assentamos a construção da sequência de ensino: o letramento estatístico e o ciclo investigativo.

\section{Marco teórico}

Muitos estudantes se perguntam: "Para quê ou por que devemos estudar Estatística?”. De fato, se ensinarmos apenas os aspectos formais dos conteúdos de Estatística, não haverá muito problema, pois os pré-requisitos matemáticos são de pouca complexidade, no máximo teremos que elevar ao quadrado uma quantidade de números. Todavia, apesar dessa simplicidade, estudos mostram que conceitos, tais como a média, desvio padrão, dentre outros, são complexos e os estudantes não conseguem se apropriar destes.

De outra sorte, a Estatística por sua natureza envolve dados e sua essência é reduzir grande quantidade destes, o que pode tornar imponderável o trabalho com dados reais em sala de aula, exigindo um preparo redobrado dos professores.

Contudo, acreditamos que para o estudante compreender o papel da Estatística, na apropriação dos fenômenos/problemas que permeiam o cotidiano, se faz necessário ensiná-lo na perspectiva do desenvolvimento do letramento estatístico, percorrendo as 
DOI: https://doi.org/10.33238/ReBECEM.2020.v.4.n.4.24142

fases do ciclo investigativo, pressupostos básicos que embasaram a construção da sequência de ensino, que detalharemos posteriormente.

\subsection{Letramento Estatístico}

Segundo Gal (2002), para que o cidadão alcance o letramento estatístico é necessário que tenha a capacidade de interpretar e avaliar criticamente as informações estatísticas e, em seguida, conseguir relacioná-las com dados e com o fenômeno do qual eles foram extraídos. Segundo Gal (2002), o letramento estatístico:

[...] refere-se, em termos gerais, a dois componentes inter-relacionados,
principalmente (a) a capacidade das pessoas de interpretar e avaliar
criticamente as informações estatísticas, os argumentos ou fenômenos
estocásticos, que elas podem encontrar em diversos contextos e, quando
relevante (b) a capacidade de discutir ou comunicar suas reações frente as
informações estatísticas, bem como a compreensão do significado da
informação, opiniões sobre as implicações das informações, ou preocupações
quanto à aceitabilidade de determinadas conclusões. (GAL, 2002, p. 2-3).

Gal (2002) propôs um modelo para o letramento estatístico que envolve dois componentes: o cognitivo e o atitudinal. O componente cognitivo é formado por cinco elementos que são: o próprio letramento; o conhecimento estatístico; o conhecimento matemático; o conhecimento do contexto e a competência para elaborar questões críticas. O componente atitudinal, por sua vez, é formado por dois elementos: crenças e atitudes; postura crítica.

Dentro do componente cognitivo ressaltamos o conhecimento de contexto, requisito imprescindível para uma pessoa compreender a Estatística que está sendo apresentada, uma vez que precisa ter familiaridade.

Desse modo, não adianta trabalharmos por exemplo, a renda per capita para analisar a desigualdade entre países, se o estudante não souber o que é Produto Interno Bruto e número de habitantes em um país, ou ainda o impacto da globalização na concentração de renda, tanto a favor de países mais desenvolvidos quanto das pessoas que já concentram a renda. Assim, quando assistimos a luta do povo chileno, entendemos que apesar de ser um país com uma renda per capita maior do que muitos países latinoamericanos, vemos que $1 \%$ da população é dona de $24 \%$ da riqueza daquele país, conforme Barrocal (2019) em reportagem à Carta Capital.

Para mais, a capacidade de elaborar questões críticas reside exatamente na capacidade de questionar se a renda per capita (média) é suficiente para compreender se 


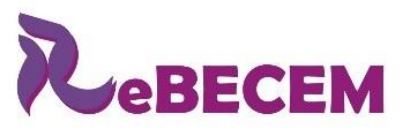

\section{Revista Brasileira de Educação em \\ Ciências e Educação Matemática}

DOI: https://doi.org/10.33238/ReBECEM.2020.v.4.n.4.24142

determinado país é desenvolvido, ou se outros indicadores são necessários para perceber melhor a situação do país, tais como a situação do desemprego, acesso à educação etc.

De outro lado, para se ter uma postura crítica não podemos desconsiderar as crenças e atitudes das pessoas, pois estas moldam suas visões de mundo; o que precisa ser trabalhado na sala de aula com os estudantes é o desenvolvimento da aptidão para uma conduta questionadora diante das informações estatísticas.

Cazorla e Utsumi (2010) afirmam que na Educação Básica o letramento estatístico não pode se limitar apenas ao contexto de leitura, mas é preciso produzir e analisar dados estatísticos em contexto e, assim, promover o desenvolvimento do pensamento estatístico, que está fortemente ligado à compreensão da tomada de decisão, em condições de incerteza, nas fases do ciclo investigativo.

\section{$4.2 \mathrm{O}$ ciclo investigativo}

Envolver os estudantes de maneira ativa em uma investigação estatística é uma estratégia pedagógica que tem fornecido bons resultados, embora demande um planejamento minucioso do trabalho, bem como preparo do professor, pois como dissemos, o imponderável pode surgir a partir dos dados reais coletados.

O ciclo investigativo - PPDAC, proposto por Wild e Pfannkuch (1999), é composto por cinco fases: Problema (compreensão da dinâmica do sistema e definição do problema); Planejamento (sistema de medição, instrumento de coleta de dados; desenho amostral; gerenciamento dos dados; teste-piloto e análises prévias); Dados (coleta de dados; gerenciamento e limpeza dos dados); Análise (análise exploratória de dados; análises planejadas; análises emergentes e geração de hipóteses) e Conclusão (interpretação, conclusão, novas ideias e comunicação)

O uso do PDDAC, em uma atividade escolar, permite aos estudantes uma postura ativa, pois eles acompanham e participam da formulação do problema, participam da elaboração da pergunta de pesquisa, refletem sobre questões tais como população, amostra, variáveis, instrumentos. Além disso, pensam a priori a natureza das variáveis e as possíveis análises que devem ser realizadas, de forma a responder à pergunta de pesquisa. Esse percurso possibilita aos estudantes utilizar os conceitos e procedimentos estatísticos em contexto. Dessa forma, ao elaborar as conclusões, as estatísticas, que foram produzidas por eles, permitem a compreensão do problema em estudo, o que pode iniciar um novo ciclo de investigação. 
DOI: https://doi.org/10.33238/ReBECEM.2020.v.4.n.4.24142

\section{Percurso metodológico}

Nesta seção apresentamos o tipo de pesquisa, os participantes, os procedimentos e a construção da sequência de ensino e da escala EPIA.

Realizamos uma pesquisa intervencionista que, como aponta Antunes, Mendonça Neto e Vieira (2016), é um tipo de pesquisa que pode contribuir para reduzir o distanciamento atual entre a academia e a prática profissional, produzindo resultados para aplicação prática imediata e fugindo do tecnicismo tradicional, uma vez que incorpora em seus resultados o conhecimento teórico e o método científico.

Para isso, construímos uma sequência de ensino pautada no ciclo investigativo PPDAC e no letramento estatístico e escolhemos como tema a percepção dos estudantes sobre o impacto do uso dos agrotóxicos.

Para apreender a percepção dos estudantes construímos uma Escala de Percepção do Impacto do uso dos Agrotóxicos, a qual denominamos de EPIA. Feito isso, nós a aplicamos antes da intervenção, percorremos as cinco fases do PPDAC, e com os dados gerados pelos próprios estudantes, eles trabalharam os diversos conceitos estatísticos adequados para o nível de ensino. Após a intervenção, novamente aplicamos a EPIA para avaliar o quanto essa percepção mudou. Desse modo, o delineamento de nossa investigação seguiu o modelo ilustrado na Figura 2.

A pesquisa foi realizada no mês de outubro de 2019, em uma turma do $3^{\circ}$ ano, do Ensino Médio, de um colégio estadual situado na cidade de um município que é produtor de alimentos hortifrúti, localizado no Vale do Jiquiriçá, no sudoeste da Bahia. Participaram 46 estudantes, todavia apenas 33 estudantes preencheram a escala EPIA antes da intervenção e 25 destes também preencheram a escala após a intervenção.

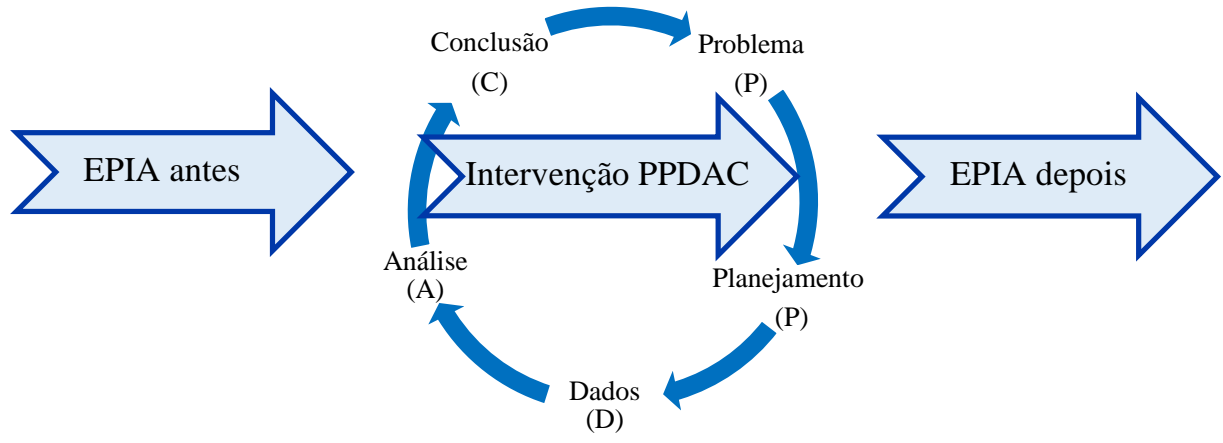

Figura 2: Delineamento da pesquisa.

Fonte: construção dos autores. 
DOI: https://doi.org/10.33238/ReBECEM.2020.v.4.n.4.24142

Os recursos utilizados na pesquisa foram: os impressos da Escala EPIA, nove reportagens que foram distribuídas aos grupos, folhas A4, canetas coloridas, lápis coloridos, borracha, régua, Datashow, lousa, pincel para quadro branco e apagador.

\subsection{A sequência de ensino}

Escolhemos o tema dos agrotóxicos porque o colégio está localizado no município de Jaguaquara, que é produtor de hortifrúti, onde frequentemente têm sido veiculadas notícias ligadas à contaminação da água, das pessoas e outros, pelo intenso uso de agrotóxicos. Além disso, os estudantes têm familiares que lidam com essa atividade e, consequentemente, de alguma forma, têm vinculação com estes produtos.

Entretanto, inquietava-nos saber até que ponto os estudantes estavam esclarecidos sobre o uso dos agrotóxicos, seus impactos e o dilema do uso versus a perda da lavoura; até que ponto eles tinham conhecimento dos diversos impactos ou se eram alienados com relação à realidade vivida pela sua comunidade. De outra parte, queríamos que os estudantes valorizassem o ensino de Estatística e como ela pode ser útil para conhecer a sua própria realidade e assim se conscientizar de seu papel, refletindo nas ações que desenvolvem dentro de sua comunidade.

Sendo assim, nós nos propusemos a realizar junto com os estudantes uma pesquisa, extraindo dados da própria realidade destes. Para tanto, percorremos as cinco fases do ciclo investigativo a fim de que eles entendessem como são realizadas as pesquisas estatísticas - desde a formulação da pergunta da pesquisa, a recolha dos dados, seu tratamento até à comunicação -, e tivessem a oportunidade de refletir como os dados são gerados, até se transformarem em estatísticas e como estas podem influenciar suas vidas. A seguir explicitamos as fases.

Problema: Teriam os estudantes a percepção, consciência e conhecimento sobre o impacto e dilemas do uso dos agrotóxicos? Como eles se posicionam diante do dilema: "usar os agrotóxicos versus a premência econômica: ou usamos ou perdemos a lavoura"? Os estudantes conhecem os diferentes impactos dos agrotóxicos, seja no meio ambiente, na saúde das pessoas ou na contaminação dos alimentos? Para guiar a discussão, distribuímos nove reportagens, a partir das quais formulamos a pergunta de pesquisa: “Qual é a percepção dos estudantes sobre o impacto do uso dos agrotóxicos?”. 
DOI: https://doi.org/10.33238/ReBECEM.2020.v.4.n.4.24142

Planejamento: Na sequência, discutimos com os estudantes questões do tipo: como podemos levantar dados para conhecer a percepção quanto ao impacto do uso dos agrotóxicos? Qual a população a ser investigada? Como delinear a amostra? Que variáveis coletar? Como realizar a análise de dados? Nesta fase, os estudantes já haviam respondido à escala EPIA, decidimos pelo preenchimento antecipado da escala para evitar a indução das respostas. Discutimos também o problema de "medir" a percepção, momento em que apresentamos as escalas do tipo Likert e, por fim, a forma como iríamos tratar os dados.

Dados: Explicamos aos estudantes que os dados foram gerados pelas suas respostas à escala EPIA, a partir da qual construímos o banco de dados e o disponibilizamos para que os estudantes conferissem seu conteúdo.

Análise: Formamos nove grupos, os quais trabalharam cada item das dimensões: impacto no meio ambiente, na saúde das pessoas e na contaminação dos alimentos. Os três itens de questões gerais foram trabalhados por um dos autores deste artigo, exemplificando como analisar os dados. Dessa forma, os estudantes foram orientados para construir a TDF ou o gráfico de barras/coluna e registrar suas conclusões.

Conclusão: para responder à pergunta de pesquisa "Qual é a percepção dos estudantes sobre o impacto do uso dos agrotóxicos?”, os estudantes ao final de suas análises, socializaram suas conclusões e finalizaram o ciclo, conforme Figura 3.

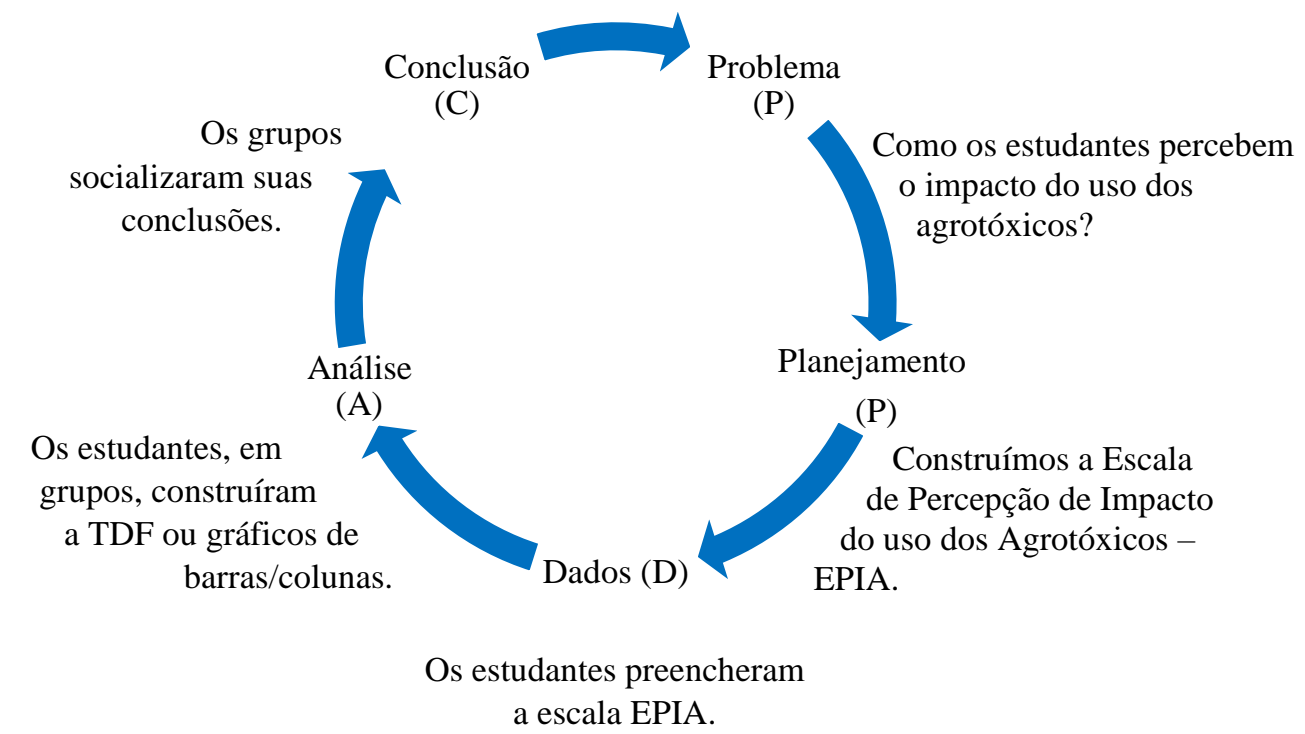

Figura 3: o ciclo investigativo da intervenção de ensino.

Fonte: construção dos autores. 


\subsection{Construção da Escala de Percepção do Impacto do uso dos Agrotóxicos - EPIA}

Segundo Cazorla, Silva-Junior e Santana (2018), a Estatística trabalha com variáveis conceituais, tais como a percepção, as atitudes, a cognição, que são inerentes ao homem e que não são perceptíveis, nem mensuráveis. Para Cazorla e Oliveira (2010, p. 120), uma "variável teórica, conceitual ou formal é aquela que não pode ser observada diretamente, mas inferida pelo comportamento dos sujeitos envolvidos na pesquisa”. Esse tipo de variável está ligado ao comportamento humano individual ou coletivo e é próprio das ciências humanas e sociais, além de ser complexo e polêmico, é difícil de ser medido, pois pode ter muitas dimensões (aspectos ou fatores) e, por isso, precisa da construção de instrumentos para ser coletado.

Nesse sentido, medir a percepção requer a elaboração de um instrumento de mensuração. Com base nos métodos e técnicas de pesquisa social, apresentados por Gil (2008), isso é possível por meio das escalas sociais que segundo ele:

[...] são instrumentos construídos com o objetivo de medir a intensidade das opiniões e atitudes da maneira mais objetiva possível. Embora se apresentem segundo as mais diversas formas, consistem basicamente em solicitar ao indivíduo pesquisado que assinale, dentro de uma série graduada de itens, aqueles que melhor correspondem à sua percepção acerca do fato pesquisado. (GIL, 2008, p. 136).

As escalas sociais permitem, como afirma Gil (2008), transformar fatos que habitualmente são vistos como qualitativos em fatos quantitativos. Um dos instrumentos de medição de percepção é a escala de Likert. Segundo Vieira e Dalmoro (2008), uma escala de Likert é composta por vários itens, sendo que cada item da escala é do tipo ordinal, com cinco proposições, das quais o respondente deve selecionar uma, podendo estas serem: "Discordo totalmente - DT", "Discordo - D" etc., conforme Figura 4.

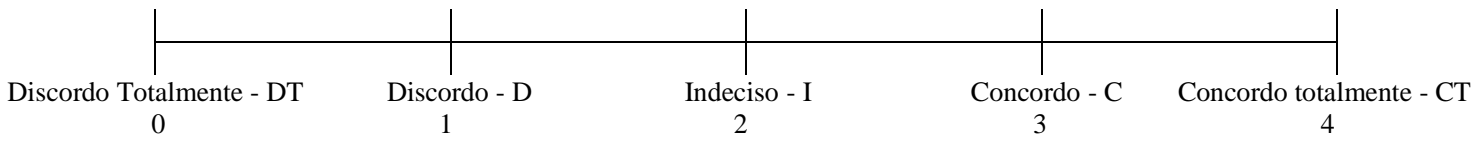

Figura 4: Modelo de escala ordinal para um item a partir da adaptação de Likert (1932).

Fonte: construção dos autores.

Essa escala ordinal é transformada em uma escala numérica, utilizando, em geral, pontuações de 1 a 5. Em nosso caso, iniciamos em 0 e fomos até 4. A escala de Likert resulta da soma da pontuação obtida em cada um dos itens que a compõem. Assim, se a escala contém 12 itens e a pontuação atribuída a cada um dos itens varia de 0 a 4, então a 


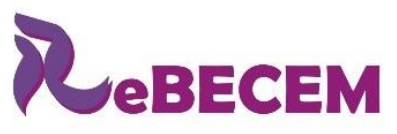

\section{Revista Brasileira de Educação em \\ Ciências e Educação Matemática}

DOI: https://doi.org/10.33238/ReBECEM.2020.v.4.n.4.24142

escala vai abarcar valores de 0 a 48 pontos. Valores próximos de 48 indicam um alto nível de concordância; valores próximos a 0 , um alto grau de discordância; e valores próximos do ponto médio (24 pontos), um nível indiferente.

De acordo com Cazorla, Silva-Junior e Santana (2018), a escala de Likert é bipolar, isto é, composta por itens de cunho positivo e negativo, via de regra, balanceada, o que implica no mesmo número de itens positivos e negativos. Neste caso, a pontuação atribuída aos itens negativos deverá ser invertida.

Dessa maneira, construímos a escala EPIA de forma a abranger quatro dimensões da percepção dos estudantes: questões gerais do agrotóxico; impactos ao meio ambiente; contaminação dos alimentos e impactos na saúde humana. Cada dimensão composta por três itens, totalizando 12, sendo sete positivos e cinco negativos. Na nossa escala, quanto maior o valor, maior percepção sobre impacto negativo do uso de agrotóxicos, conforme Quadro 1.

\begin{tabular}{|c|c|c|}
\hline Dimensão & Itens & Sentido \\
\hline \multirow{3}{*}{$\begin{array}{l}\text { Questões } \\
\text { Gerais }\end{array}$} & 1. É viável produzir alimentos sem agrotóxicos & Positivo \\
\hline & 2. Existe um movimento contra os agrotóxicos, mas eu acho exagerado & Negativo \\
\hline & $\begin{array}{l}\text { 3. O agrotóxico garante a produção de alimento e ajuda no combate à fome no } \\
\text { mundo }\end{array}$ & Negativo \\
\hline \multirow{3}{*}{$\begin{array}{l}\text { Meio } \\
\text { Ambiente }\end{array}$} & 4. A água potável é livre de agrotóxicos & Negativo \\
\hline & 5. Os agrotóxicos fragilizam e reduzem a fertilidade do solo & Positivo \\
\hline & $\begin{array}{l}\text { 6. Agrotóxico disseminado pelo ar, contamina as pessoas através das vias } \\
\text { respiratórias }\end{array}$ & Positivo \\
\hline \multirow{3}{*}{ Alimentos } & 7. A dieta dos brasileiros é rica em agrotóxicos & Positivo \\
\hline & 8. Lavar e higienizar bem folhas, legumes e frutas retira o agrotóxico & Negativo \\
\hline & 9. $70 \%$ dos alimentos in natura consumidos no Brasil estão contaminados & Positivo \\
\hline \multirow{3}{*}{ Pessoas } & $\begin{array}{l}\text { 10. O perigo do agrotóxico é para quem manipula, e não para quem } \\
\text { consome }\end{array}$ & Negativo \\
\hline & $\begin{array}{l}\text { 11. O Agrotóxico entra no corpo em contato com a pele, mucosas, } \\
\text { respiração ou ingestão }\end{array}$ & Positivo \\
\hline & $\begin{array}{l}12 . \\
\text { bebê }\end{array}$ & Positivo \\
\hline
\end{tabular}

Quadro 1: Respostas dos estudantes nos 12 itens da escala EPIA.

Fonte: construção dos autores.

A análise dos resultados foi dividida em dois momentos: no primeiro, de cunho qualitativo, dedicamo-nos a responder à pergunta de pesquisa, analisando as interações entre um dos autores e os estudantes na implementação da sequência de ensino; no segundo momento, realizamos uma análise estatística sobre o impacto na percepção dos estudantes utilizando a pontuação na escala EPIA antes e depois da intervenção.

Os dados foram codificados e transcritos para a planilha Excel, posteriormente para o software Statistical Package for the Social Sciences (SPSS), versão 20. Para o 


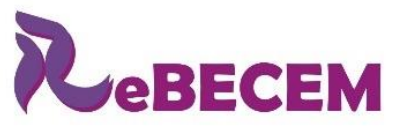

DOI: https://doi.org/10.33238/ReBECEM.2020.v.4.n.4.24142
Revista Brasileira de Educação em

Ciências e Educação Matemática

ISSN 2594-9179

tratamento estatístico da pontuação dos estudantes na escala EPIA utilizamos a estatística descritiva, o teste $t$-student e de Wilcoxon para amostras emparelhadas, bem como a análise de correlação e regressão para analisar as possíveis mudanças na percepção antes e depois da intervenção. O nível de significância utilizado foi de 5\%.

\section{Resultados}

Como anunciamos, os resultados serão apresentados em dois momentos: o primeiro dedicado à implementação da intervenção de ensino e o segundo à análise da percepção dos estudantes antes e depois da intervenção.

\subsection{Análise da intervenção de ensino}

Para responder ao questionamento de como uma intervenção de ensino, pautada no letramento estatístico e no ciclo investigativo, promove a aprendizagem de conceitos estatísticos em contexto, construímos uma sequência de ensino e a intervenção de ensino foi implementada em seis aulas de 50 minutos cada, totalizando 300 minutos.

No primeiro momento, os estudantes responderam à escala EPIA. Em seguida, iniciamos a primeira fase do ciclo investigativo: a definição do Problema. Para isso, apresentamos um mapa interativo que mostra a quantidade de agrotóxicos encontrados na água potável de municípios brasileiros, em especial do município dos participantes da pesquisa, dialogando sobre os pontos positivos e negativos dos agrotóxicos.

Na sequência, os estudantes foram orientados a formar nove grupos para trabalhar os nove itens das três dimensões da escala EPIA: contaminação dos alimentos, danos ao meio ambiente e à saúde das pessoas. Os grupos foram sinalizando o tema de seu interesse. Cada grupo recebeu uma reportagem, totalizando nove reportagens, com um tema relacionado ao item da escala EPIA, contendo dados estatísticos.

Os estudantes discutiram com os integrantes do seu grupo, sinalizando o que consideraram importante. Foi proposta uma exposição com as considerações de cada grupo em relação à reportagem que recebeu e foi aberta a participação dos demais grupos para fazerem acréscimos.

No momento da exposição das discussões dos grupos, os estudantes apresentaram casos reais de contaminação por agrotóxico. Por exemplo, ao discutir a reportagem 


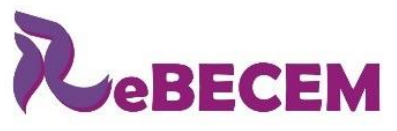

Revista Brasileira de Educação em

Ciências e Educação Matemática

DOI: https://doi.org/10.33238/ReBECEM.2020.v.4.n.4.24142

intitulada "Intoxicação por agrotóxicos pode levar à cegueira e até à morte; conheça histórias de vítimas", publicada pelo Globo Rural (2019), os estudantes citaram vários exemplos ocorridos com seus familiares e conhecidos. Nesse sentido, uma estudante relatou que ao comer bananas de uma bananeira contaminada com agrotóxicos, ela e seus familiares vomitaram sangue. Outra estudante sinalizou que a mãe sente fortes dores de cabeça quando trabalha na lavoura pulverizada com agrotóxico.

Os estudantes do grupo que recebeu a reportagem de Sanchez (2017), intitulada “Agrotóxicos causam má-formação em bebês no Brasil e nos EUA, apontam estudos", demostraram grande surpresa, pois eles não imaginavam que os agrotóxicos pudessem ter um impacto desse nível. E sinalizaram que responderam "Negativo", no pré-teste, para a afirmação "Pai ou mãe contaminados por agrotóxicos implica na má formação do bebê".

Os estudantes também demonstraram surpresa ao ler a reportagem sobre a contaminação dos alimentos pelos agrotóxicos, quando fizeram a associação dos alimentos listados como os mais contaminados e os mais produzidos no município, como é o caso da abobrinha, alface e tomate. O município está entre os dez primeiros produtores agrícolas na Bahia, estando em primeiro lugar na produção de abacate, em quarto lugar de maracujá (IBGE, 2018) e em terceiro lugar como produtor de tomate (IBGE, 2007).

Ainda sobre o tema de alimentos, uma estudante acrescentou que no momento da colheita, a depender do alimento, come-se os frutos, tirando diretamente do "pé", sem lavar. Outro estudante completou dizendo que quando pulveriza a plantação com agrotóxico, os alimentos ficam com uma nata branca na superfície e que não são lavados antes de embalar para a venda.

Com relação aos temas relacionados à contaminação ao meio ambiente, os estudantes não ficaram surpresos com o fato de o munícipio onde vivem aparecer na lista da reportagem adaptada de Lyrio e Vigné (2019), que apresenta as mais de 271 cidades da Bahia com água contaminada por agrotóxicos. Eles acrescentaram que conhecem a barragem que abastece a cidade, sendo que está rodeada de plantações e que consequentemente recebe muito agrotóxico.

Discutindo sobre a reportagem de Carneiro (2015) que tratava das embalagens dos agrotóxicos como indicadores de contaminação e os dados do Dossiê ABRASCO, que fornece o destino de embalagens de agrotóxicos de estabelecimentos rurais, alguns estudantes informaram que queimavam parte das embalagens, outros não se manifestaram sobre esses descartes. 


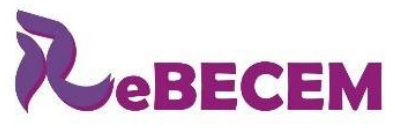

DOI: https://doi.org/10.33238/ReBECEM.2020.v.4.n.4.24142
Revista Brasileira de Educação em

Ciências e Educação Matemática

ISSN 2594-9179

Ao finalizar a discussão interna dos grupos, a turma foi questionada sobre o tema comum nos textos lidos, concluindo que todas as reportagens falavam de agrotóxicos, danos à saúde e ao meio ambiente. No entanto, percebemos durante a discussão, que os grupos não faziam menção aos gráficos e tabelas presentes nas reportagens, apenas aos dados estatísticos destrinchados no texto, o que sinalizava a pouca familiaridade dos estudantes com a leitura de tabelas e gráficos, dando-nos pistas para a condução de nosso trabalho.

Após as leituras e discussões, seguimos para a formulação do Problema a ser investigado em sala de aula e todos concordaram que seria: "Qual é a percepção dos estudantes sobre os impactos do uso de agrotóxicos?".

Na fase do Planejamento, discutimos com os estudantes o que é população, amostra, variáveis empíricas e conceituais, e apresentamos a construção da escala EPIA, com dados referentes à percepção destes sobre os impactos dos agrotóxicos na contaminação dos alimentos, na saúde e ao meio ambiente. Houve o delineamento do tratamento dos dados, a fim de que os estudantes aplicassem os conceitos estatísticos estudados. Explicamos que o ideal teria sido construir a escala de forma conjunta, mas devido ao tempo, levamos a escala EPIA pronta. A turma concordou com os itens contemplados.

Na fase Dados, com os dados coletados a partir do preenchimento da escala EPIA, construímos o banco de dados e entregamos uma cópia a cada grupo, que trabalhou com um dos itens da escala. Cada grupo, decidiu, de forma livre, a melhor forma de organizar os dados (tabela ou gráfico), de modo que uma mensagem, em relação ao tema, fosse transmitida ao leitor de maneira compreensível podendo acrescentar outras informações decorrentes da discussão ou de pesquisas na internet.

Foi proposto que os grupos fizessem uma manchete ou cartaz informativo relacionado ao tema do item que foi analisado, da escala EPIA, cuja construção deveria conter um gráfico de barras ou coluna. A escolha desses gráficos ocorreu pela facilidade de construção, tendo em vista a limitação do tempo para desenvolver a sequência de ensino. Nesse momento, deu-se início à fase de Análise, construindo as tabelas de distribuição de frequência e/ou os gráficos.

Na Figura 5, apresentamos a construção da TDF, do gráfico de colunas e a análise realizada pelo grupo que ficou com o item "A dieta dos brasileiros é rica em agrotóxico". Observamos que os estudantes realizaram a contagem de forma adequada e construíram corretamente os eixos e as colunas do gráfico, embora tenham esquecido de nomear os 
DOI: https://doi.org/10.33238/ReBECEM.2020.v.4.n.4.24142

eixos. Quanto à análise, os estudantes conseguiram fazer a leitura de que a maioria concordou com a afirmação do item, mas ressaltaram: "porém, um número significante discordou", se referindo aos nove estudantes $(27,3 \%)$ que sinalizaram DT e D, o que dá sinais da existência de certo nível de letramento estatístico.
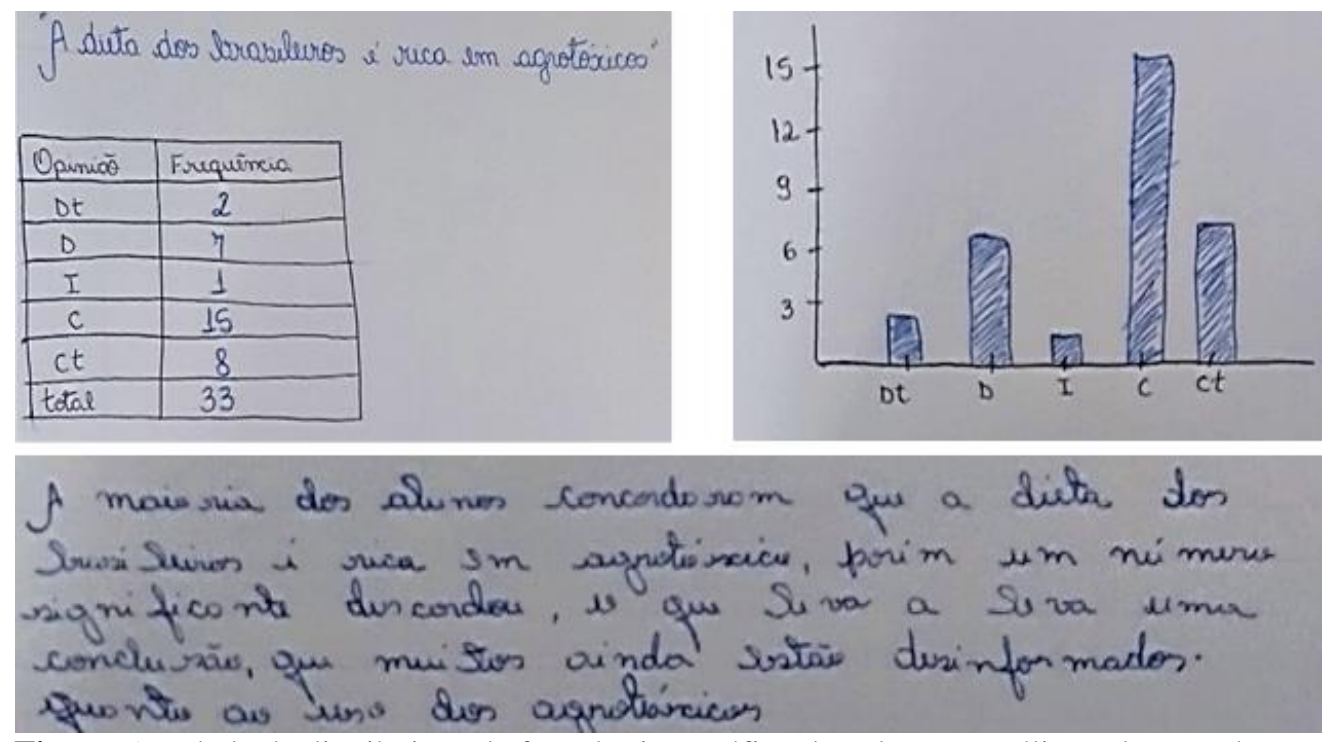

Figura 5: Tabela de distribuição de frequências, gráfico de colunas e análise pelos estudantes. Fonte: acervo dos autores.

Na Figura 6 apresentamos a produção do grupo que trabalhou o item "A água potável é livre de agrotóxicos" e observamos que os estudantes optaram pelo gráfico, embora tenham cometido um pequeno deslize na calibração da escala, pois o espaçamento do 0 a 5 não é o mesmo dos restantes.

Todavia, estes estudantes conseguiram fazer conexões com outras reportagens que encontraram por meio de pesquisa autônoma na internet, pois as afirmações: "Apenas $25 \%$ dos municípios brasileiros monitoram a presença de resíduos químicos na água potável, como metais pesados, solventes, derivados de desinfecção domésticas e agrotóxicos" e "Brasil é o maior consumidor mundial de agrotóxicos" são trechos das reportagens de Oliveira (2018) e de Santos (2019) respectivamente, que não foram disponibilizadas na discussão em sala. 
DOI: https://doi.org/10.33238/ReBECEM.2020.v.4.n.4.24142
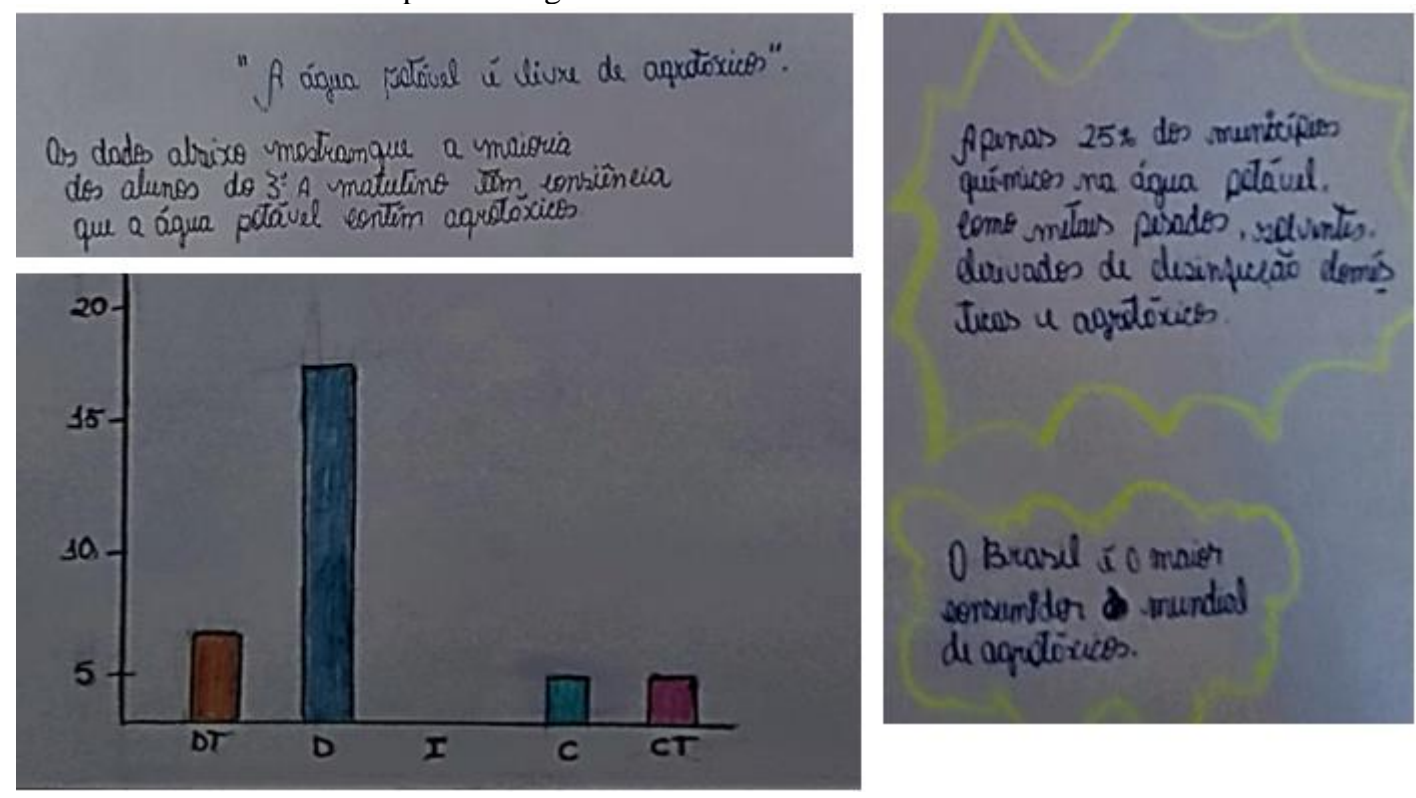

Figura 6: Gráfico de colunas, análise dos dados e balões informativos construído pelos estudantes. Fonte: acervo dos autores.

O grupo que trabalhou o item "O perigo do agrotóxico é para quem manipula e não para quem consome" construiu o gráfico de barras (Figura 7), de forma sucinta, colocando apenas o título, mas não teceram comentários. Com relação à percepção dos estudantes verificamos que eles estão bastante conscientes, pois a maioria discordou ou discordou totalmente da afirmação.

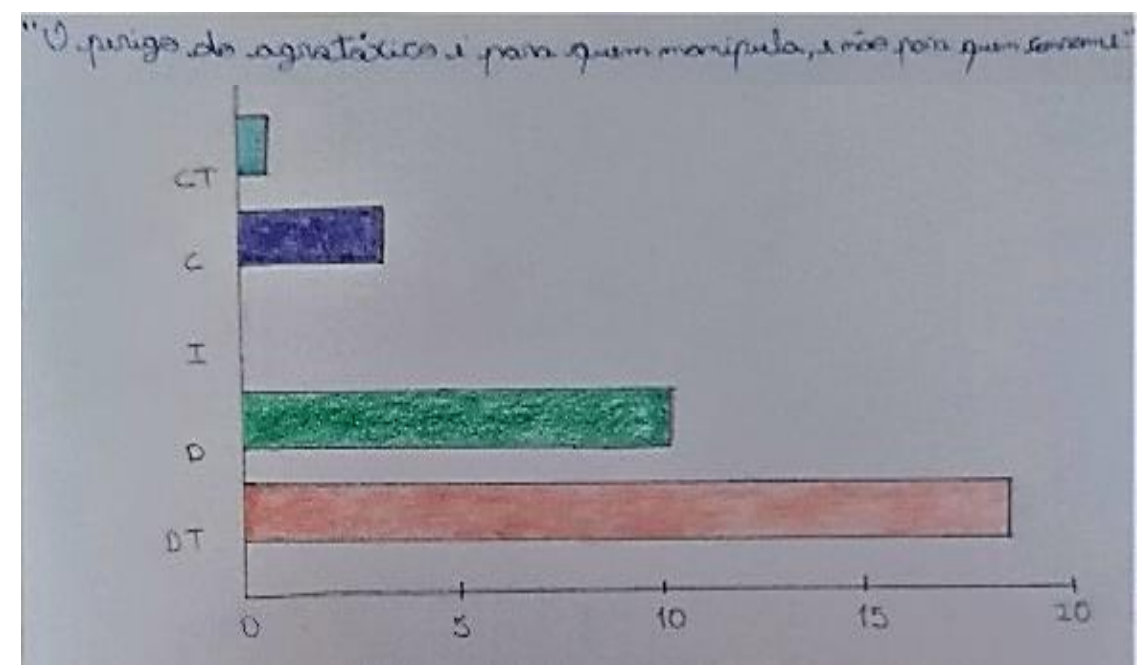

Figura 7: Gráfico de barras construído pelos estudantes.

Fonte: acervo dos autores.

Os outros grupos também expuseram seus resultados com estruturas semelhantes, demonstrando o letramento estatístico proposto por Gal (2002), fruto do envolvimento na discussão sobre os temas com o apoio nos dados estatísticos presentes nas reportagens, relacionando-os com os dados coletados na escala EPIA e com os dados coletados de outras fontes, de forma autônoma. 
DOI: https://doi.org/10.33238/ReBECEM.2020.v.4.n.4.24142

Por fim, na fase da Conclusão, os grupos socializaram seus resultados em sala e responderam à pergunta de pesquisa elaborada, afirmando que pelas exposições dos demais colegas, sobre os itens da escala, eles tinham uma percepção quanto aos impactos do uso de agrotóxicos. E acrescentaram que mudariam algumas respostas em relação ao que responderam, inicialmente, na escala EPIA, pois descobriram novas informações sobre os agrotóxicos.

Na Figura 8 apresentamos a distribuição das respostas aos 12 itens da escala e pudemos perceber que os estudantes tenderam a concordar nos itens positivos e a discordar nos itens negativos. Isso demonstra que os estudantes não estão alienados e que têm uma postura crítica diante da problemática do uso dos agrotóxicos. Entretanto, foi possível perceber e eles próprios afirmaram que não tinham conhecimento sobre alguns aspectos nocivos dos agrotóxicos e que reveriam suas respostas.

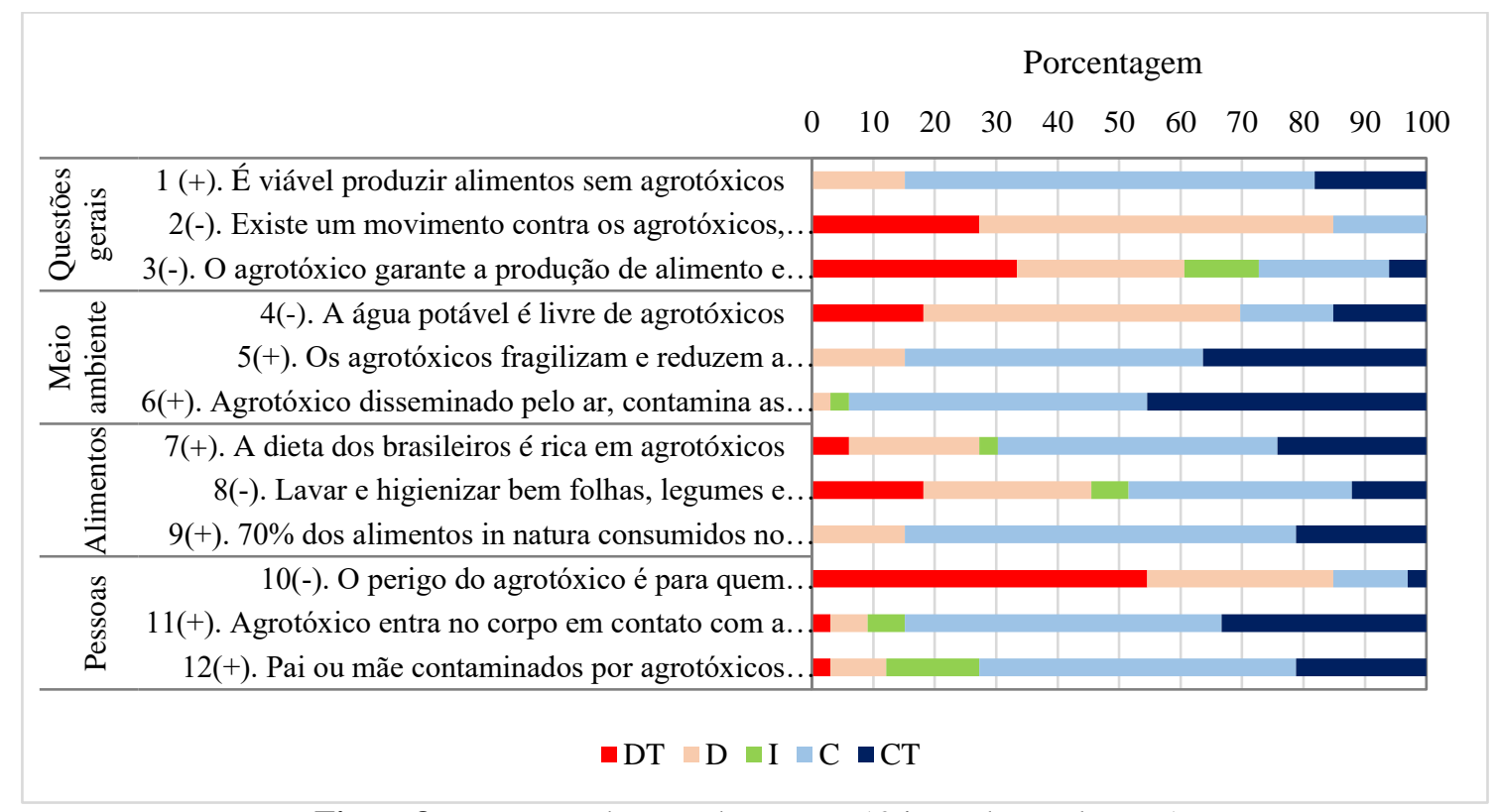

Figura8: Respostas dos estudantes aos 12 itens da escala EPIA.

Fonte: construção dos autores.

Encerrada a fase de conclusão, os estudantes responderam a escala EPIA novamente e comentaram que gostaram muito da intervenção de ensino, questionando o porquê de terminar tão rápido.

Foi aberto um espaço para comentar sobre tudo que foi feito na sequência de ensino e pontuaram que "nem se toda aula de Matemática fosse assim", "assim é mais fácil" e demostraram contentamento pelas produções, especialmente pela experiência de investigar e construir os próprios gráficos e com dados produzidos em sala. 


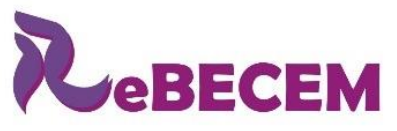

Revista Brasileira de Educação em

Ciências e Educação Matemática

DOI: https://doi.org/10.33238/ReBECEM.2020.v.4.n.4.24142

Os estudantes tiveram um espaço para avaliar o trabalho realizado com a intervenção de ensino, sinalizando os pontos positivos e negativos, como também apresentando sugestões. Nesse momento, afirmaram que só houve pontos positivos, pois, além de aprender o conteúdo eles descobriram muitas coisas sobre agrotóxicos, inclusive ficaram espantados com o quanto ele é prejudicial. E a sugestão foi ampliar o tempo para a realização desse tipo de trabalho.

\subsection{Análise da percepção dos estudantes na escala EPIA}

Na Tabela 1 apresentamos as estatísticas da pontuação na escala EPIA dos estudantes antes e depois da intervenção, de forma global e depois por zona de residência do estudante. Na Figura 9 apresentamos a distribuição da pontuação tanto antes e depois da intervenção, quanto por zona de residência. Esta análise está restrita aos 25 estudantes que responderam a escala EPIA antes e depois da intervenção.

Quanto à pontuação na escala EPIA, observamos que antes da intervenção esta variou de 22 a 46, com média de 34,04 pontos, isso denota que os estudantes se posicionaram de forma crítica com respeito aos diferentes impactos dos agrotóxicos, o que foi aguçado pela intervenção, pois a pontuação mínima subiu para 29 e a média para 37,08 pontos.

Quando analisamos os dados por zona de residência, para nossa surpresa, verificamos que os estudantes da zona rural apresentaram pontuação menor do que os estudantes da zona urbana, porém apresentaram um ganho maior após a intervenção, passando de 31,43 pontos para 36,29 , sendo significativo a $10 \%$; já os da zona urbana passaram de 35,06 pontos para 37,39, sendo essa diferença significativa conforme Tabela 1. Devido ao pequeno número de dados por zona, realizamos o teste não paramétrico de Wilcoxon, ratificando os resultados do teste $t$-student.

Tabela 1: Pontuação na escala EPIA, antes e depois da intervenção e zona de residência

\begin{tabular}{|c|c|c|c|c|c|c|c|}
\hline \multirow{2}{*}{$\begin{array}{l}\text { Zona de } \\
\text { residência }\end{array}$} & \multirow[b]{2}{*}{ Intervenção } & \multicolumn{3}{|c|}{ Estatísticas } & \multicolumn{3}{|c|}{ Teste $t$-student } \\
\hline & & $\mathrm{N}$ & Média & Desvio padrão & $\mathrm{t}$ & $\begin{array}{l}\text { Graus de } \\
\text { liberdade }\end{array}$ & p-valor \\
\hline \multirow{2}{*}{ Todos } & Antes & 25 & 34,04 & 6,093 & \multirow{2}{*}{$-3,220$} & \multirow{2}{*}{24} & \multirow{2}{*}{0,004} \\
\hline & Depois & 25 & 37,08 & 4,618 & & & \\
\hline \multirow{2}{*}{ Rural } & Antes & 7 & 31,43 & 6,477 & \multirow{2}{*}{$-2,367$} & \multirow{2}{*}{6} & \multirow{2}{*}{0,056} \\
\hline & Depois & 7 & 36,29 & 4,152 & & & \\
\hline \multirow{2}{*}{ Urbana } & Antes & 18 & 35,06 & 5,805 & \multirow{2}{*}{$-2,261$} & \multirow{2}{*}{17} & \multirow{2}{*}{0,037} \\
\hline & Depois & 18 & 37,39 & 4,865 & & & \\
\hline
\end{tabular}

Fonte: construção dos autores. 
DOI: https://doi.org/10.33238/ReBECEM.2020.v.4.n.4.24142

Apesar de os estudantes da zona rural terem apresentado uma pontuação média menor antes da intervenção, essa diferença não foi significativa segundo o teste $t$-student de amostras independentes $\left(t_{(23)}=1,360 ; p=0,187\right)$. Após a intervenção, a diferença entre a zona de residência diminuiu substancialmente e, também, não foi significativa $\left(t_{(23)}=\right.$ $0,528 ; p=0,602)$.
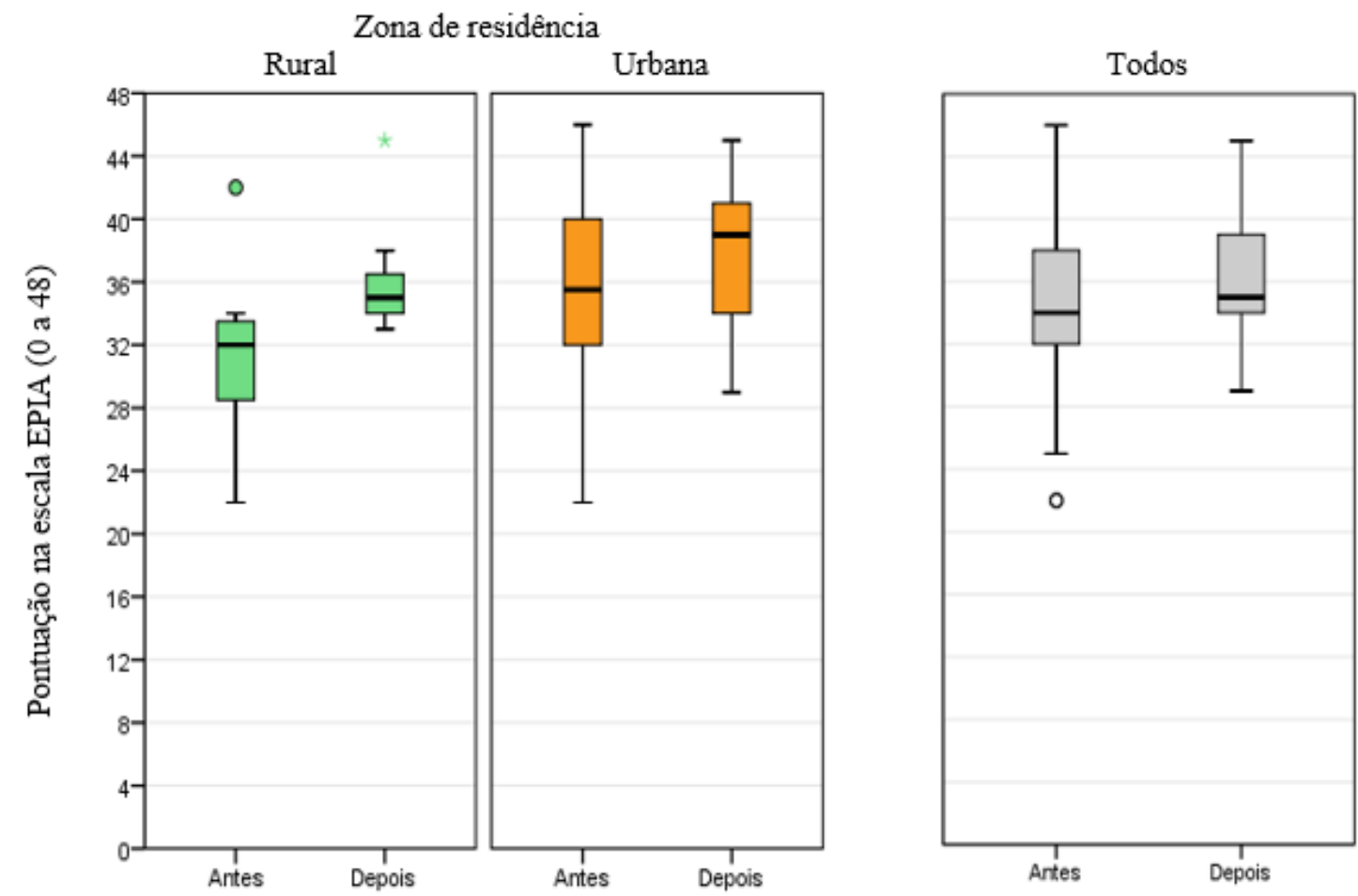

Intervenção de ensino

Figura 9: Distribuição da pontuação na escala EPIA, antes e depois da intervenção e zona de residência.

Fonte: construção dos autores.

Na Figura 10 apresentamos a relação entre a pontuação antes e depois da intervenção, verificamos que a correlação foi de 0,643 e a reta de regressão foi $\mathrm{Y}=$ 0,487X $+20,502$, com um coeficiente de determinação de 41,3\%. Além disso, podemos perceber que se traçássemos os eixos no ponto médio da escala ( 24 pontos para X e para Y) verificaríamos que apenas dois pontos caem fora do I quadrante, isto é, os estudantes não eram alienados, posicionaram-se de forma crítica e a intervenção de ensino aguçou essa criticidade. 


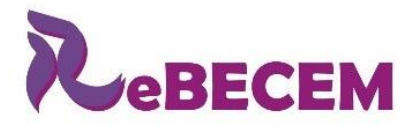

DOI: https://doi.org/10.33238/ReBECEM.2020.v.4.n.4.24142

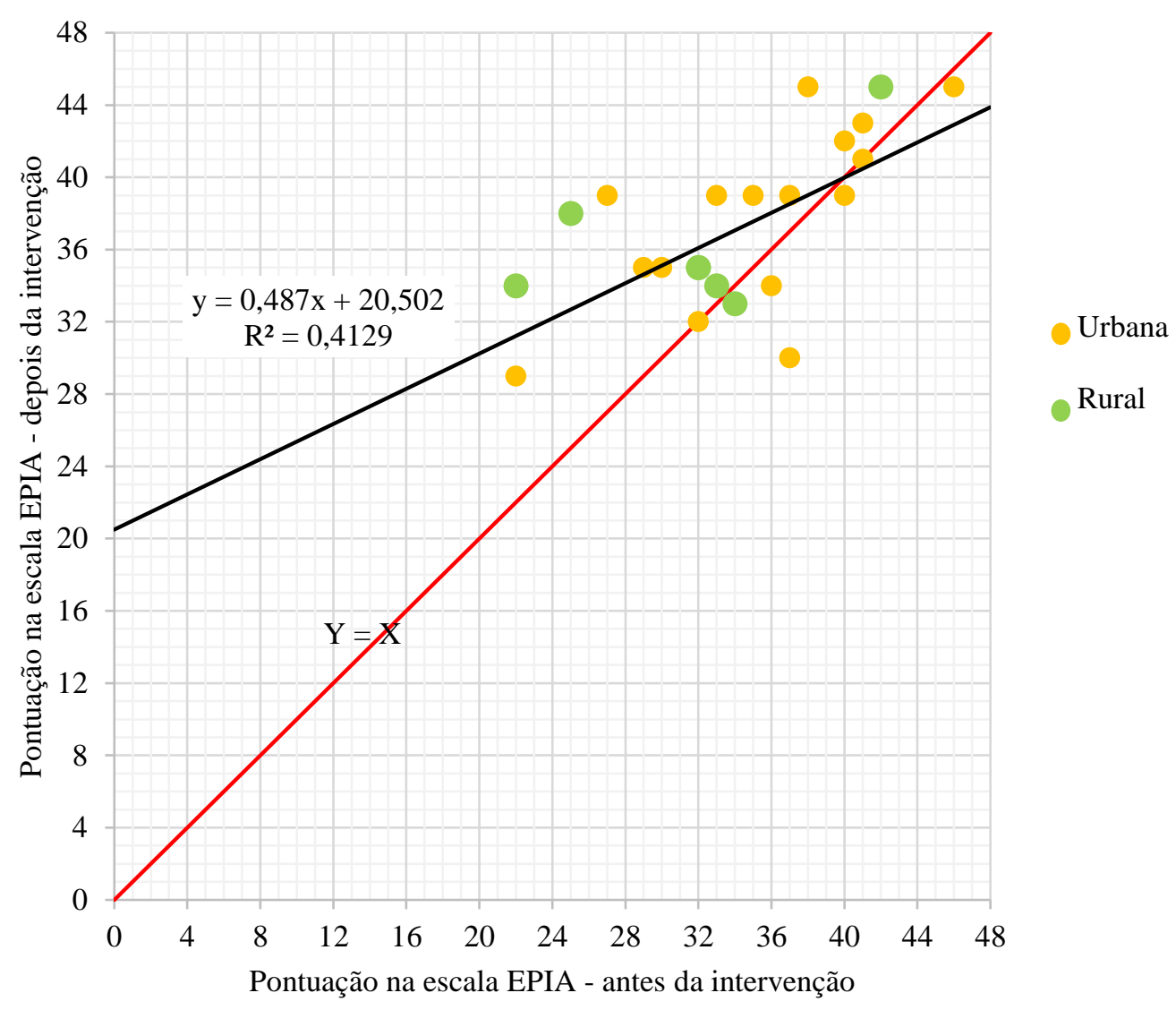

Figura 12: Relação entre a pontuação na escala EPIA, antes e depois da intervenção e zona de residência. Fonte: construção dos autores.

\section{Considerações finais}

Este trabalho teve por objetivo analisar o desenvolvimento e implementação de uma sequência de ensino que visou a apropriação dos conceitos estatísticos em contexto, tendo por tema agrotóxicos e com base no letramento estatístico e no ciclo investigativo.

Na implementação da intervenção de ensino, os resultados mostram, por um lado, que os estudantes ao se envolverem em todo o processo investigativo conseguem realizar as atividades estatísticas e dão sentido às estatísticas produzidas. Os resultados são promissores quanto ao engajamento dos estudantes e a apropriação dos conceitos estatísticos. Foi alentador verificar que os estudantes não se limitaram às reportagens levadas pelas autoras, mas de forma autônoma pesquisaram na internet trabalhos relevantes e os utilizaram para consolidar seus argumentos, isto é, percebemos que a intervenção de ensino promoveu a potencialização da capacidade de argumentação, conforme preconizado pela BNCC. 


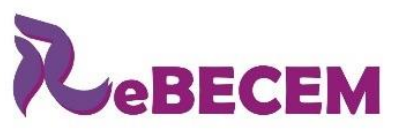

Revista Brasileira de Educação em

Ciências e Educação Matemática

DOI: https://doi.org/10.33238/ReBECEM.2020.v.4.n.4.24142

Observamos que o tema era significativo para os estudantes, pois muitos deles e suas famílias dependem da agricultura e, nesse sentido, como professores, sugerimos que é importante observar temas de relevância social da comunidade escolar, a fim de engajálos ativamente.

Como desafios, verificamos que o professor deve reservar pelo menos três seções de duas horas-aulas para implementação da sequência, além de realizar um planejamento detalhado a fim de saber lidar com os dados reais. Ademais, com o tempo limitado não foi possível explorar com os estudantes outros resultados, como o uso das respostas que eles forneceram depois da intervenção. Tal ação poderia contribuir para comparar as respostas de antes, no intuito de verificar o quanto eles mudaram suas posições em cada item; essa ação também permitiria trabalhar com a pontuação da escala, na qual podem ser aplicadas as estatísticas resumos, como as medidas de tendência central e dispersão, por exemplo.

No que refere a percepção dos estudantes antes e depois da intervenção de ensino, notamos que esta foi aguçada. Os estudantes não eram alienados, se posicionaram de forma crítica em relação aos diferentes impactos dos agrotóxicos durante o desenvolvimento da sequência de ensino, o que influenciou no aumento da média de pontos da percepção.

Por fim, almejamos encorajar a comunidade educacional a promover 0 engajamento dos estudantes para que eles sejam os grandes atores de sua aprendizagem. A Estatística é, portanto, uma ferramenta poderosa para compreender a realidade e contribuir com cidadãos capazes de se posicionar em um mundo em constante mudança.

\section{Referências}

ANTUNES, Maria Thereza P., MENDONÇA NETO, Octavio R.; VIEIRA, Almir M. Pesquisa intervencionista e mestrados profissionais: perspectivas de sua prática nos cursos da área de gestão. Indagatio Didactica, Cidade de Publicação, v. 8, n. 3, p. 53-68, 2016. Disponível em <https://proa.ua.pt/index.php/id/article/view/2569>. Acesso em 22 de nov. de 2019.

BARROCAL, A. Chile tem a terceira maior concentração de renda no $1 \%$ mais rico. Carta Capital, 2019. Disponível em: <https://www.cartacapital.com.br/mundo/chile-tem-a-terceiramaior-concentracao-de-renda-no-1-mais-rico/>. Acesso em 26 de fev. de 2020. 
DOI: https://doi.org/10.33238/ReBECEM.2020.v.4.n.4.24142

BRASIL. Lei $\mathbf{n}^{\mathbf{0}} \mathbf{7 . 8 0 2}$, de 11 de julho de 1989. Dispõe sobre a pesquisa, a experimentação, a produção, a embalagem e rotulagem, o transporte, o armazenamento, a comercialização, a propaganda comercial, a utilização, a importação, a exportação, o destino final dos resíduos e embalagens, o registro, a classificação, o controle, a inspeção e a fiscalização de agrotóxicos, seus componentes e afins, e dá outras providências. Disponível em <http://www.planalto.gov.br/ccivil_03/LEIS/L7802.htm>. Acesso em 09 de nov. de 2019.

BRASIL. Lei $\mathbf{n}^{0}$ 9.795, de 27 de abril de 1999. Dispõe sobre a educação ambiental, institui a Política Nacional de Educação Ambiental e dá outras providências. Diário Oficial da União, Brasília, 28 de abril de 1999. Disponível em:

<http://www.planalto.gov.br/ccivil_03/leis/L9795.htm>. Acesso em 15 de nov. de 2019.

BRASIL. Ministério da Educação (MEC). Base Nacional Comum Curricular. Brasília, 2018. Disponível em:

<http://basenacionalcomum.mec.gov.br/images/BNCC_EI_EF_110518_versaofinal_site.pdf>. Acesso em 15 nov. 2019.

CARNEIRO, Fernando F. (Org.) Dossiê ABRASCO: um alerta sobre os impactos dos agrotóxicos na saúde. Rio de Janeiro: EPSJV; São Paulo: Expressão Popular, 2015.

CAZORLA, Irene M; OLIVEIRA, Marcelo S. Para saber mais. In: CAZORLA, I. M.; SANTANA, E. R. S. (Org.). Do tratamento da informação ao letramento estatístico. Itabuna, BA: Via Litterarum, 2010.

CAZORLA, Irene M.; SILVA JÚNIOR, A. V.; SANTANA, E. R. DOS S. Reflexões sobre o ensino de variáveis conceituais na Educação Básica. Revista de Ensino de Ciências e Matemática, v. 9, n. 2, p. 354-373, 28 maio 2018.

CAZORLA, Irene M.; UTSUMI, Miriam C. Reflexões sobre ensino de Estatística na Educação Básica. In I. M. CAZORLA; E. SANTANA (Org.). Do tratamento da informação ao letramento estatístico. Itabuna, BA: Via Litterarum, 2010.

FERNANDES, Carolina S.; STUANIL, Geovana M. Agrotóxicos no Ensino de Ciências: uma pesquisa na educação do campo. Educação \& Realidade, Porto Alegre, v. 40, n. 3, p. 745-762, 2015.

GAL, Iddo. Adults' Statistical Literacy: Meanings, Components, Responsibilities. International Statistical Review, Voorburg, v. 70, n. 1, p. 1-25, abr. 2002.

GIL, A. C. Métodos e técnicas de pesquisa social. Sexta Edição. São Paulo: Atlas, 2008.

GLOBO RURAL. Intoxicação por agrotóxicos pode levar à cegueira e até à morte; conheça histórias de vítimas. Rio de Janeiro, 31, março de 2019. Disponível em <https://g1.globo.com/economia/agronegocios/globo-rural/noticia/2019/03/31/intoxicacao-por- 
DOI: https://doi.org/10.33238/ReBECEM.2020.v.4.n.4.24142

agrotoxicos-pode-levar-a-cegueira-e-ate-a-morte-conheca-historias-de-vitimas.ghtml >. Acesso em 10 de nov. de 2019.

IBAMA. Relatórios de comercialização de agrotóxicos. Disponível em:

<http://ibama.gov.br/agrotoxicos/relatorios-de-comercializacao-de-agrotoxicos>. Acesso em 10 de nov. de 2019.

IBGE, Produção Agrícola Municipal 2006. Rio de Janeiro: IBGE, 2007.

IBGE, Produção Agrícola Municipal 2018. Rio de Janeiro: IBGE, 2018.

INCA. Agrotóxico. Rio de Janeiro: INCA, 2009. Disponível em:

<www.inca.gov.br/alimentacao/agrotoxicos>. Acesso em 10 de novembro de 2019.

LYRIO, Alexandre; VIGNÉ, Júlia. 271 cidades da Bahia têm água contaminada por agrotóxicos. Correio, Salvador, 21 de abril de 2019. Disponível em

$<$ https://www.correio24horas.com.br/noticia/nid/271-cidades-da-bahia-tem-agua-contaminadapor-agrotoxicos-veja-lista/>. Acesso em 21 de nov. de 2019.

OLIVEIRA, Cida de. Água livre de agrotóxicos é meta de projeto do Ministério Público do Trabalho. Brasil de Fato, São Paulo, 22 de março de 2018. Disponível em $<$ https://www.brasildefato.com.br/2018/03/22/agua-livre-de-agrotoxicos-e-meta-de-projeto-doministerio-publico-do-trabalho>. Acesso em 14 de nov. de 2019.

SANCHEZ, Isabela. Agrotóxicos causam má-formação em bebês no Brasil e nos EUA, apontam estudos. De olho nos Ruralistas, 2017. Disponível em $<$ https://deolhonosruralistas.com.br/2017/10/06/agrotoxicos-causam-ma-formacao-em-bebesno-brasil-e-nos-eua-apontam-estudos/ >. Acesso em 20 de out. de 2019.

SANTANA, Eurivalda. R. S.; CAZORLA, Irene M. Desenvolvimento profissional de professores que ensinam Matemática. Projeto de pesquisa. Universidade Estadual de Santa Cruz, Ilhéus, Bahia, Brasil, 2018.

SANTOS, Gil. Brasil é o maior consumidor de produtos com agrotóxicos do mundo. Correio. Salvador, 05 de setembro de 2019. Disponível em <https://www.correio24horas.com.br/noticia/nid/brasil-e-o-maior-consumidor-de-produtoscom-agrotoxicos-do-mundo>. Acesso em 14 de nov. de 2019.

VIEIRA, K. M.; DALMORO, M. Dilemas na construção de escalas tipo Likert: o número de itens e a disposição influenciam nos resultados? In: ENANPAD, XXXII, 2008, Rio de Janeiro. Anais... Rio de Janeiro: ANPAD, 2008. Disponível em http://www.anpad.org.br/admin/pdf/EPQ-A1615.pdf. Acesso em 10 de nov. de 2019. 
DOI: https://doi.org/10.33238/ReBECEM.2020.v.4.n.4.24142

WILD, Chris J.; PFANNKUCH, Maxine. Statistical Thinking in Empirical Enquiry. International Statistical Review, Voorburg, v. 67, n.3, p. 223-265, 1999.

WODEWOTZKI, M. L. L.; JACOBINI, O. R. O Ensino de Estatística no Contexto da Educação Matemática. In: BICUDO, M. A. V.; BORBA, M. C. (Org.). Educação Matemática: Pesquisa em Movimento. São Paulo: Editora Cortez, 2004. p. 232-249.

Recebido em: 28 de fevereiro de 2020

Aceito em: 17 de setembro de 2020 